\title{
Retrospective clinic and urodynamic study in the Neurogenic Bladder Dysfunction caused by Human T Cell Lymphotrophic Virus Type 1 Associated Myelopathy / Tropical spastic paraparesis (HAM/TSP)
}

\author{
O Troisgros, F Naghibzadeh Darbon, JL Barnay, P Olive, F Komminoth, P René-Corail
}

From 17th International Conference on Human Retroviruses: HTLV and Related Viruses

Trois llets, Martinique. 18-21 June 2015

\section{Introduction}

HTLV-I -associated tropical spastic paraparesis (TSP) and HTLV-I associated myelopathy (HAM) is an endemic disease in Carribean Island. Bladder-sphincter dysfunctions are almost present. Functional disablement is major. Few studies are devoted to urinary disablement, responsible for urologic complications, that gives one of the elements of the severity prognosis of the disease. The objectives of the study are first to describe clinic and urodynamic characteristics of voiding disorders in Martiniquan population, secondly evaluate if there is a relationship between motor and urinary handicap, and thirdly evaluate prognosis factors of urologic complications.

\section{Methods}

Retrospective study of 60 patients suffering from HAM/ TSP. Clinical, urodynamic datas, scale of urinary and motor handicap (MHU and Osame Score) were collected. For qualitative variables, the distribution of the frequencies associated is calculated. For quantitative variables, means are calculated. Chi2 test was used to compare percentages, means comparison test to compare qualitative and quantitative datas.

\section{Results}

Irritative symptoms were the most frequent (75\%) whatever type of detrusor activity. Detrusor over activity was the most frequent disorder (75.61\%). Bladder compliance was normal in half percent of the cases. Urethral activity

\footnotetext{
Service MPR-CHU Fort De France
} 